\title{
Measurement of cervical length using transvaginal sonography for prediction of preterm labour
}

\author{
Bina M. Raval, Viditsinh P. Sisodiya*, Pushpa A. Yadava, \\ Shital T. Mehta, Sagar R. Patel, Bintu H. Dadhania
}

Department of Obstetrics and Gynecology, Smt. NHL municipal medical college, SVPIMSR, Ahmedabad, Gujarat, India

Received: 06 August 2020

Accepted: 15 September 2020

*Correspondence:

Dr. Viditsinh P. Sisodiya,

E-mail: sisodiya.vidit@gmail.com

Copyright: (c) the author(s), publisher and licensee Medip Academy. This is an open-access article distributed under the terms of the Creative Commons Attribution Non-Commercial License, which permits unrestricted non-commercial use, distribution, and reproduction in any medium, provided the original work is properly cited.

\section{ABSTRACT}

Background: Preterm labour and delivery cause major health burden to the society due to high perinatal morbidities and mortality and long-term health implications and also affects maternal. An effective and objective way for predicting preterm delivery is measurement of cervical length by transvaginal sonography as it allows better quality and accurate visualization of uterine cervix. Cervical length $(<25 \mathrm{~mm})$ is good and accurate cervical biometry for prediction of preterm birth. The objective of this study was to measure cervical length by transvaginal sonography for predicting preterm labour and fetal outcome.

Methods: This prospective observational study was conducted in department of obstetrics and gynaecology, at SVPIMSR hospital, Ahmedabad from July 2018 to December 2019 in 150 antenatal women to assess cervical changes (cervical length, dilatation of internal OS, funnelling etc.) between 16 to 24 weeks of gestation and these cases followed till delivery and results were analysed.

Results: 150 antenatal women who fulfilled the selection criteria were studied using transvaginal ultrasound between 16-24 weeks of gestation, out of them 36 (24\%) women delivered preterm babies. The sensitivity, specificity, positive predictive value (PPV) and negative predictive value (NPV) recorded in this study were 80.5\%, 94.73\%, 82.85\% and $93.91 \%$ respectively.

Conclusion: Transvaginal sonography is the most useful and better, safe, accurate, most effective, less expensive, objective and acceptable technique for assessing cervical length in all antenatal women and predicting the preterm labour when assessed between 16-24 weeks of gestational age.

Keywords: Preterm labour, Preterm birth, Cervical length, Transvaginal sonography

\section{INTRODUCTION}

An average duration of normal pregnancy is 40 weeks (280 days) from first day of last menstrual period or 267 days after conception. Preterm labour is defined by WHO onset of labour after 20 weeks of gestation but before 37 weeks of gestation regardless of birth weight. ${ }^{1}$ Preterm is the leading cause of neonatal morbidity and mortality and its prevention is an important healthcare priority. ${ }^{2}$ In spite of with improved healthcare facilities and perinatal care, the incidence of preterm is still rising. ${ }^{3-5}$
Preterm complicates $5-10 \%$ of pregnancies but accounts for $85 \%$ of perinatal morbidity and mortalities. ${ }^{6}$ Every year, an estimated 15 million babies are born preterm and this number is rising. It's like 1 in 10 babies is born prematurely. Approximately, 1 million children die each year due to complications of preterm. Globally, prematurity is the leading cause of neonatal deaths among children of age less than 5 years. Preterm accounts for large number of complications related death when compared to other causes. ${ }^{7,8}$ 
In India, among the total 27 million babies born annually, 3.6 million babies are born preterm, and over 3,00,000 of these preterm babies die each year because of associated complications. ${ }^{9}$ India with its largest number of preterm births and largest number of preterm deaths worldwide, contributes $25 \%$ of the overall preterm related deaths. Despite substantial efforts to introduce new therapies for prevention, it continues to contribute significantly to neonate and infant mortality. The effects of preterm births extend beyond the early infancy with substantial long-term consequences in late childhood and adult life. ${ }^{9}$

Preterm birth also affects maternal health, such as anxiety, fatigue, flashbacks, and depression issues related to preterm birth and future development of their babies, Such mothers had less early contact with babies, more postnatal problems, less positive response towards the babies in early months after delivery, even they suffer from their own maternal health related issues such as hypertension, diabetes, maternal infections and other maternal risk factors for preterm that leads to maternal complications such as placental abruption, placenta previa, maternal infection and inflammation etc. Mothers of preterm babies had less early contact with their babies due to their own health and prolonged NICU admission of their babies, they face more post-natal health problems, substantially fewer positive feelings towards their baby and made less use of the support health system available. $^{10}$

Risk factors for preterm labour are prior history of preterm labour, short cervix, history of any cervical surgeries like cervical conisation, polyhydramnios, fetal anomaly, placental abruption, placental previa and uterine malformations, threatened miscarriage, cervical infection (bacterial vaginosis), maternal inflammation and fever (UTI and other causes), uteroplacental insufficiency (ex. Hypertension, diabetes, drug abuse, smoking, alcohol consumption), extremes of maternal age, low socioeconomic status, low pre-pregnancy weight, psychological factors, stress etc.

Based on gestational age preterm divides in subcategories $^{8}$ : Extremely preterm (less than 28 weeks), Very preterm (28 to 32 weeks) and moderate to late preterm (32 to 37 weeks).

Prevention of preterm delivery can be achieved only when there is a better screening test and availability of treatment strategies which can be applied on both symptomatic and asymptomatic pregnant women. Treatment of risk factors can also help to delay and prevent preterm labour such as treatment of maternal inflammation and infection with antibiotic prophylaxis (bacterial vaginosis, UTI, periodontal disease), women with history of repeated miscarriage, past history of preterm labour and twin gestation are candidates for prophylactic cervical cerclage and vaginal and oral progesterone. $^{11}$
Methods like demographic features, obstetrics history, assessment of uterine contractions, biochemical markers, fern test, fetal fibronectin levels, sterile speculum examination of cervix, digital examination of cervix to assess dilatation and effacement of cervix, sonographic evaluation of cervix: transabdominal and transvaginal. ${ }^{12-}$ 15

Transvaginal sonography emerged as an alternative to measure cervical length and assess its morphology, to establish the risk of developing preterm labour. This study was conducted to ascertain the role of cervical length measurement by transvaginal sonography as predictor of preterm delivery.

\section{METHODS}

A Prospective observational study was conducted in the department of obstetrics and gynaecology, at SVPIMSR hospital, Ahmedabad, Gujarat, India from July 2018 to December 2019 to determine correlation between cervical length and preterm labour using transvaginal sonography.

Inclusion criteria included asymptomatic Women with singleton pregnancy, gestational age between 16 -24 weeks of gestation and women with h/o previous first or second trimester miscarriages, past history of spontaneous preterm labour.

Exclusion criteria excluded multiple gestation, placenta previa or abruption, fetal anomaly, polyhydramnios, history of any cervical surgeries that lead to cervical incompetence, pregnancy with pre-eclampsia, severe IUGR, RH isoimmunisation, gestational diabetes and symptomatic women who went under interventions like cervical cerclage, tocolysis, or aborted during study.

150 antenatal patients who presented to OPD for routine antenatal visits were included in the study. A detailed history and examination were done and an informed and written consent were taken for the procedure was obtained after explaining the procedure in detail.

Measurement of cervical length with Transvaginal sonography was done between 16-24 weeks of gestation and they were called for follow up after 3-4 weeks. Cut off cervical length was $25 \mathrm{~mm}$. If cervical length was more than $25 \mathrm{~mm}$, further follow up scan was not done. If cervical length was $<25 \mathrm{~mm}$, those women were called for follow up scan after 3-4 weeks.

\section{Cervical length measurement technique}

Before conducting the procedure, all antenatal women were asked to empty their bladder. Antenatal woman placed in dorsal position, a transvaginal probe covered with lubricated condom inserted and guided by anterior vaginal fornix, sagittal long axis view of endocervical along with cervical length was obtained. High frequency endovaginally probe $(5-7 \mathrm{MHz})$ was used. 
The length of cervix from external OS to internal OS was measured along with endocervical canal. Cervical changes like funnelling, funnel length, width index and anterior and posterior cervical width were noted. Three measurements were obtained and shortest in $\mathrm{mm}$ was recorded. All antenatal patients were followed up till their delivery and details regarding their delivery, baby and associated complications were recorded.

Here we mention some images that show progressive cervical changes and cervical measurement technique:

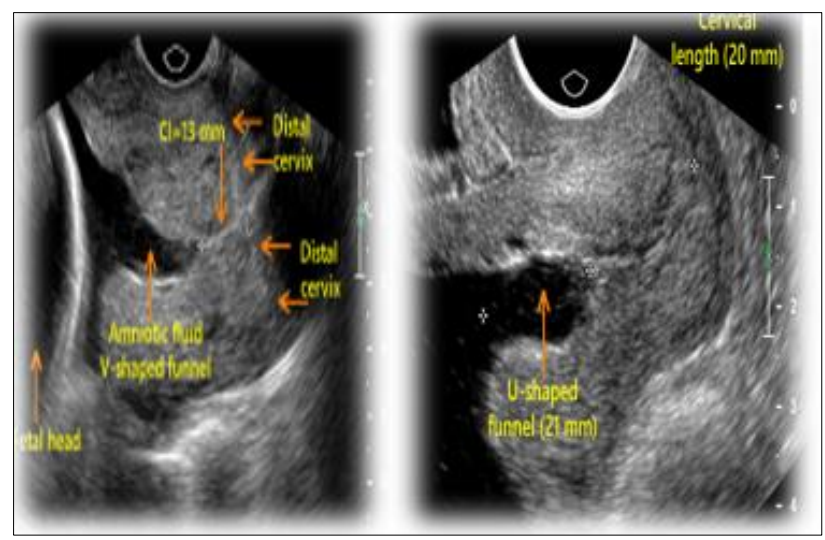

Figure 1: Progressive cervical shape changes in transvaginal sonography.

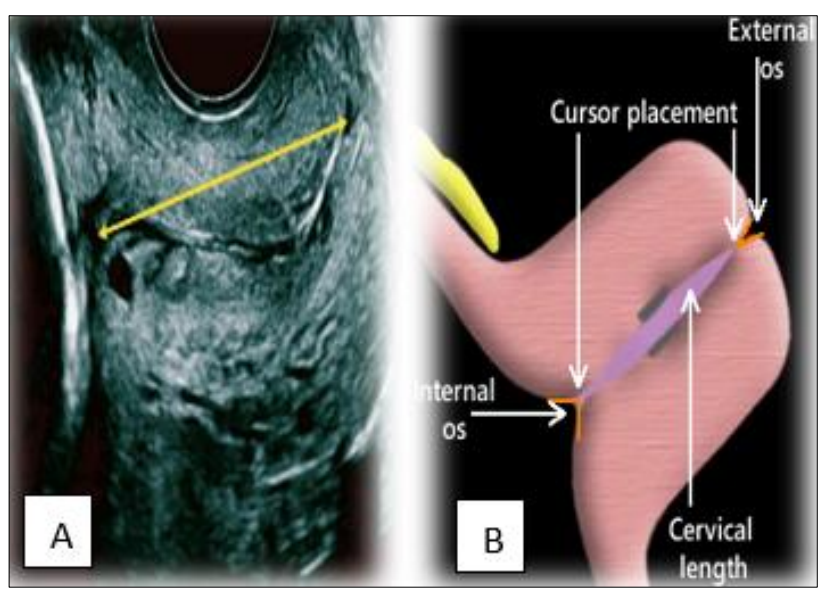

Figure 2: (A) Transvaginal ultrasound image. (B) Diagrammatic image of measurement of cervical length from external OS to internal OS.

\section{RESULTS}

150 antenatal women who fulfilled the selection criteria were enrolled for the study and divided in the different groups. According to the age wise distribution of patients, maximum number of antenatal patients were found in the age group of 21-25 years (46\%) and least number of antenatal patients were found in the age group of $>30$ years $(3 \%)$ (Table 1$)$.
Table 1: Age wise distribution of all patients.

\begin{tabular}{|lll|}
\hline Age (Years) & No. & Percentage (\%) \\
\hline $\mathbf{1 8 - 2 0}$ & 50 & 33 \\
\hline $\mathbf{2 1 - 2 5}$ & 69 & 46 \\
\hline $\mathbf{2 6 - 3 0}$ & 27 & 18 \\
\hline $\mathbf{3 0}$ & 4 & 3 \\
\hline Total & 150 & 100 \\
\hline
\end{tabular}

All antenatal patients were divided according to their parity status. Most of the patients were multiparous, accounts for $62 \%$. While, $38 \%$ accounts for primigravida patients (Table 2).

Table 2: Distribution of cases according to parity.

\begin{tabular}{|lll|}
\hline Parity & No. & Percentage (\%) \\
\hline P1 & 57 & 38 \\
\hline P2 & 59 & 39 \\
\hline P3 & 29 & 19 \\
\hline P4 & 3 & 2.5 \\
\hline P5 & 2 & 1.5 \\
\hline Total & 150 & 100 \\
\hline
\end{tabular}

Among 150 antenatal women, 35 women had cervical length $<25 \mathrm{~mm}$ on transvaginal sonography when measured between 16-24 weeks of gestation out of them, 29 had preterm delivery and 06 had term delivery. Rest of the 115 women had cervical length $>25 \mathrm{~mm}$ when measured by transvaginal sonography between 16-24 weeks of gestation, 07 had preterm delivery and 108 had term delivery (Table 3 ).

Table 3: Obstetric outcome in relation to cervical length.

\begin{tabular}{|llll|}
$\begin{array}{l}\text { Cervical length } \\
(\mathbf{m m})\end{array}$ & $\begin{array}{l}\text { No. of } \\
\text { patients }(\%)\end{array}$ & $\begin{array}{l}\text { Term } \\
(\%)\end{array}$ & $\begin{array}{l}\text { Preterm } \\
(\%)\end{array}$ \\
\hline$<\mathbf{2 5}$ & 35 & 6 & 29 \\
& $(23.33)$ & $(17.14)$ & $(82.86)$ \\
\hline $\mathbf{2} 25$ & 115 & 108 & 7 \\
& $(76.67)$ & $(93.91)$ & $(6.09)$ \\
\hline Total & 150 & 114 & 36 \\
\hline
\end{tabular}

According to age wise distribution (Figure 3), 50 women were from 18-20 age group (33\%) delivered 4 preterm babies. 69 women were from 21-25 years age group $(46 \%)$ delivered 23 preterm babies, 27 women were from 25-30 years age group (18\%) delivered 07 preterm babies, 4 women were from $>30$ age group (3\%) delivered 1 preterm baby.

In figure 4 among all the study population, number of preterm deliveries is more in Multigravida $23(65.71 \%)$ as compared to primigravida 12 (34.29\%). 


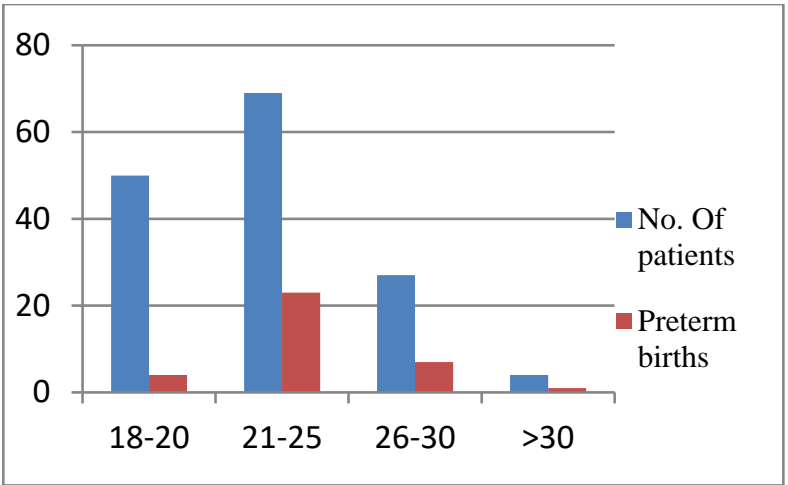

Figure 3: Age wise correlation between study population and preterm labour.

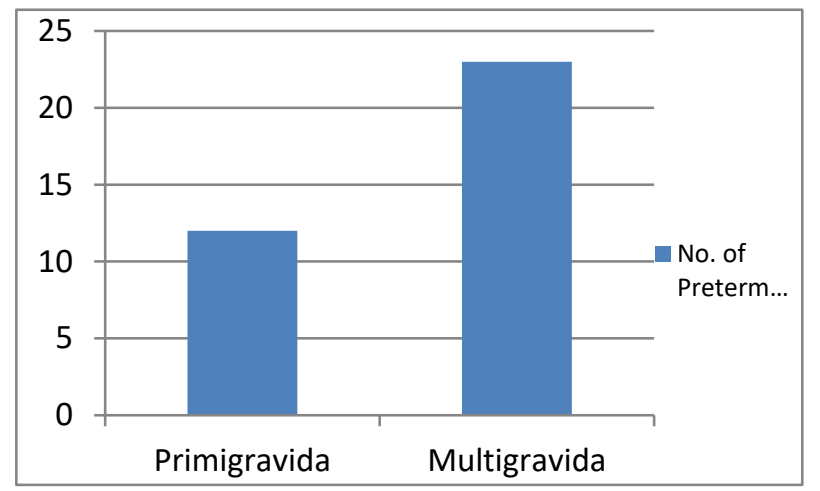

Figure 4: Comparison of preterm deliveries between primigravida and multigravida.

Table 4: Distribution of cases according to birthweight.

\begin{tabular}{|lll|}
\hline Birth weight $(\mathrm{kg})$ & No. & Percentage (\%) \\
\hline $\mathbf{2} . \mathbf{5}$ & 33 & 22 \\
\hline $\mathbf{2 . 5 - 3 . 0}$ & 93 & 62 \\
\hline $\mathbf{> 3 . 0}$ & 24 & 16 \\
\hline Total & 150 & 100 \\
\hline
\end{tabular}

93 number of babies had birth weight in the range of 2.5$3.0 \mathrm{~kg}, 24$ babies were above $3.0 \mathrm{~kg}$ and 33 babies were below $2.5 \mathrm{~kg}$ (Table 4).

Table 5: Sensitivity, specificity, PPV and NPV among study population.

\begin{tabular}{|ll|}
\hline Variables & Percentage $(\%)$ \\
\hline Sensitivity & 80.55 \\
\hline Specificity & 94.73 \\
\hline PPV & 82.85 \\
\hline NPV & 93.91 \\
\hline Accuracy & 91.33 \\
\hline
\end{tabular}

The sensitivity, specificity, PPV, NPV and accuracy of this study were $80.5 \%, 94.7 \%, 82.8 \%, 93.9 \%$ and $91.3 \%$ respectively (Table 5).

\section{DISCUSSION}

Preterm labour and delivery contribute to a major health burden to the society due to high perinatal morbidities and mortality. Preterm labour complicates 5-10\% pregnancies but accounts for $85 \%$ morbidities and mortalities. ${ }^{6}$ Preterm labour is responsible for major neonatal deaths due to low birth weight and its complications. Despite of latest and improved health care expenditure the incidence of preterm is still rising. ${ }^{3-5}$

Risk of preterm labour is high among the women with short cervical length. Cervical changes begin with the progressive funnelling of the internal OS that progress towards external OS.

These cervical changes are usually established before changes in external OS, begins early in pregnancy that leads to preterm delivery.

Transvaginal ultrasonography is the most useful screening and diagnostic tool to diagnose short cervical length during early pregnancy and helps to predict preterm labour in early pregnancy. It is superior, safe and more accurate than digital examination, transabdominal or transperineally ultrasound. Studies show that there is relation between cervical length and risk of preterm labour, decreased cervical length increases the risk of preterm labour.

In present study 35 pregnant women had cervical length $<25 \mathrm{~mm}$ on transvaginal sonography when measured during early pregnancy. Out of them, 29 had preterm deliveries and 06 had term deliveries. 115 patients had cervical length $>25 \mathrm{~mm}$, out of them 07 had preterm deliveries and 108 had term deliveries.

Most of the patients were of younger age group (21-25 years) and had the greatest number of preterm deliveries like 23 out of 35 . The number of preterm deliveries were more in multigravida (23) in compare to primigravida (12).

The sensitivity, specificity, PPV and NPV recorded in this study were $80.5 \%, 94.73 \%, 82.85 \%$ and $93.91 \%$ respectively.

Studies done by Hernandez-Andrade et al and Friedman et al showed such results which can be correlated with this study, they showed us that Transvaginal ultrasound was the superior and accurate method for assessment of cervical length than transabdominal ultrasound. ${ }^{16-17}$

Here, mentioning study results such as sensitivity, specificity, PPV and NPV of different studies predicting preterm labour using cervical length using transvaginal sonography with this study: 
Table 6: Comparison of sensitivity, specificity, PPV and NPV of cervical length for predicting preterm labour in different studies.

\begin{tabular}{|c|c|c|c|c|c|c|c|}
\hline Author & $\begin{array}{l}\text { Study } \\
\text { population }\end{array}$ & $\begin{array}{l}\text { Gestational } \\
\text { weeks }\end{array}$ & $\begin{array}{l}\text { Cut off cervical } \\
\text { length }(\mathrm{mm})\end{array}$ & $\begin{array}{l}\text { Sensitivity } \\
(\%)\end{array}$ & $\begin{array}{l}\text { Specificity } \\
(\%)\end{array}$ & $\begin{array}{l}\text { PPV } \\
(\%)\end{array}$ & $\begin{array}{l}\text { NPV } \\
(\%)\end{array}$ \\
\hline Iams et al $(1996)^{18}$ & 2915 & 24 & $<20$ & 23 & 97 & 26 & 97 \\
\hline Dennis et al $^{19}$ & 2915 & $<35$ & $<25$ & 47 & 84 & 35 & 90 \\
\hline Kore et al $(2009)^{20}$ & 115 & $22-24$ & $<30$ & 57.6 & 97.6 & 89.5 & 89.2 \\
\hline 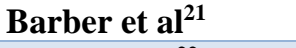 & 2351 & $18-22$ & $<29$ & 26 & 98 & 63.6 & 93.57 \\
\hline Davies et al $^{22}$ & 964 & $24-28$ & $<30$ & $57 \%$ & $82 \%$ & $4.5 \%$ & 99.2 \\
\hline Ghose $(\mathbf{2 0 1 4})^{23}$ & 130 & $22-24$ & $<25$ & 40.6 & 96.9 & 81.3 & 83.3 \\
\hline $\begin{array}{l}\text { Sethumadhvan } \\
(2017)^{24}\end{array}$ & 442 & $20-24$ & $<25$ & 100 & 93.46 & 8 & 100 \\
\hline Reddy $(2018)^{25}$ & 134 & $16-24$ & $<25$ & 75 & 95.2 & 50 & 98.4 \\
\hline Pushprajb $(2018)^{26}$ & 130 & $16-20$ & $<25$ & 70.9 & 63.2 & 63.7 & 70.5 \\
\hline Present study & 150 & $16-24$ & $<25$ & 80.5 & 94.73 & 82.85 & 93.91 \\
\hline
\end{tabular}

Study done by Liam et al for role of transvaginal ultrasound in measurement of cervical length to predict preterm labour found that transvaginal sonography was very safe, acceptable, effective and accurate method for prediction of preterm labour. ${ }^{27}$ Cervical length was reported to be inversely proportional to the risk of preterm birth in asymptomatic women.

In comparison with the data of various mentioned studies the sensitivity, specificity, PPV and NPV values of this study were better. In this study cut off cervical length was $25 \mathrm{~mm}$. And values of the sensitivity, specificity, PPV and NPV recorded in this study were $80.5 \%, 94.73 \%$, $82.85 \%$ and $93.91 \%$ respectively.

The accuracy of this study was $91.33 \%$, therefore the accuracy of Transvaginal sonography is to measure cervical length specific in predicting preterm labour. The ultrasound examination of uterine cervix by vaginal route was the main focus of this study and it has been proved that transvaginal sonography of the cervix is better, safe, accurate and effective than manual examination or any other variable to measure cervical length and for predicting preterm labour.

\section{CONCLUSION}

From above study, it was concluded that Transvaginal sonography is the most useful, better, safe, accurate, noninvasive, most effective, less expensive, objective and acceptable OPD technique for assessing cervical length in all antenatal women and predicting the preterm labour in comparison to other cervical biomarkers. It is very useful screening tool to assess cervical length for prediction of preterm labour in asymptomatic and high-risk women. Apart from assessment of cervical length fetal anomalies can be ruled out during transvaginal ultrasound assessment. A shorter cervical length was found to be associated with risk of preterm delivery. This study confirms the findings of different previous studies which showed that there is an inverse relation between the cervical length and risk of preterm labour.

Transvaginal sonography helps to diagnose women with short cervical length $<25 \mathrm{~mm}$ and it is also helpful in women with risk factors such as history of preterm labour, repeated miscarriage, cervical dystocia or funnelling and etc. So, by TVS can diagnose them early and prevent and delay preterm labour by treating maternal infection, inflammations, prophylactic cervical encerclage and vaginal or oral progesterone and tocolysis.

Funding: No funding sources

Conflict of interest: None declared

Ethical approval: The study was approved by the Institutional Ethics Committee

\section{REFERENCES}

1. Creasy RK, Resnik R. Creasy and Resnik's Maternal-Fetal Medicine: Principle and Practice, $7^{\text {th }}$ edi, Saunders Elsevier, Philadelphia; 2009;1320.

2. Behrman RE, Butler AS (eds). Committee on Understanding Premature Birth and Assuring Healthy Outcomes, Board on Health Sciences Policy. Preterm Birth Causes, Consequences, and Prevention, Institute of Medicine of the National Academies. The National Academies Press: Washington DC. 2007.

3. Joseph KS, Kramer MS, Wu Wen S, Alexander D. Determinants of preterm birth in Canada from 1981through 1992, and 1992 through 1994. N Engl J Med. 1998;339:1434-9.

4. Peri Stats. White Plains, NY: March of Dimes; 2006. Available from: http://www.marchofdimes.com/peristats/. Accessed on April 2006.

5. Callaghan WM Mac Dorman MF, Rasmussen SA, Qin C, Lackritz EM. The contribution of preterm birth to infant mortality rates in the United States. Pediatrics. 2006;118:1566-73. 
6. Goswami K, Thornton S. The prevention and treatment of preterm labor. In: Progress in Obstetrics and Gynaecology. Vol. 17. NewDelhi: John Studd, Edinburg, Churchill Livingstone; 2006.

7. Liu L, Oza S, Hogan D, Chu Y, Perin J, Zhu J et al. Global, regional, and national causes of under-5 mortality in 2000-15: an updated systematic analysis with implications for the Sustainable Development Goals. Lancet. 2016;388(10063):3027-35.

8. WHO. Available at: https://www.who.int/newsroom/fact-sheets/detail/preterm-birth WHO article. Accessed on 05/07/2020.

9. Department of Biotechnology, Ministry of Science and Technology (2014) Programme launched to identify causes of premature births, Sep 02, 2014.

10. Henderson J, Carson C, Redshaw M. Impact of preterm birth on maternal well-being and women's perceptions of their baby: a population-based survey. BMJ Open. 2016;6:e012676.

11. Cunningham FG, Leveno KJ, Bloom SL, Dashe JS, Hoffman BL, Casey BM et al, Chapter 42, Williams Obstetrics 25th Edition, Mc Graw Hill Education. 2018; 1358 .

12. Lockwood CJ, Senyei AE, Dische MR, Casal D, Shah KD, Thung SN. Fetal fibronectin in cervical and vaginal secretions as a predictor of preterm delivery. N Eng J Med 1991;325(10):669-74.

13. American College of Obsterticians and Gynecologists: Preterm Labour. Technical Bulletin No. 206. Int J Gynaecol Obstet. 1995;50(3):303-13.

14. Hueston WJ. Preterm contractions in community settings: II. Predicting preterm birth in women with preterm contractions. Obstet Gynecol. 1998;92:43-6.

15. Macones GA, Segel SY, Stamilio DM, Morgan MA. Predicting delivery within 48 hours in women treated with parenteral tocolysis. Obstet Gynecol.1999;93:432-6.

16. Hernandez-Andrade E, Romero R, Ahn H, Hussein Y, Yeo L, Korzeniewski SJ et al. Evaluation of uterine cervical length during pregnancy fails to identify a substantial number of women with a short cervix. J Matern Fetal Neonatal Med. 2012;25(9):1682-9.

17. Friedman AM, Srinivas SK, Parry S, Elovitz MA, Wang E et al. Can transabdominal ultrasound be used as a screening test for short cervical length? Am J Obstet Gynecol. 2013;208(3):190:1-7.

18. Iams JD, Goldenberg RL, Meis PJ, Mercer BM, Moawad A, Das A et al. The length of the cervix and the risk of spontaneous premature delivery. National
Institute of Child Health and Human Development Maternal Fetal Medicine Unit Network. N Engl J Med. 1996;334:567-72.

19. Dennis JG, Berghella V. Cervical length and prediction of preterm delivery. Obstet Gynecol. 2007;19:191-5.

20. Kore SJ, Parikh MP, Lakhotia S, Kulkarni V, Ambiye VR. Prediction of risk of preterm delivery by cervical assessment by trans vaginal ultrasonography. J Obstet Gynecol India. 2009;59:131-5.

21. Barber MA, Eguiluz I, Plasencia W, Medina M, Valle L, Garcia JA. Preterm delivery and ultrasound measurement of cervical length in Gran Canaria, Spain. Int J Obstet Gynecol. 2010;108(1):58-60.

22. Davies G, Ottenhof C, Woodman M, Farley A, Julien N, Van VD et al. Cervix length and relaxing as predictors of preterm birth. J Obstet Gynaecol Can. 2008;30:1124-31.

23. Ghose S, Samal S, Armugam S, Parida P. Measurement of cervical biometry using transvaginal ultrasonography in predicting preterm labor. J Nat Sc Biol Med. 2014;5:369-72

24. Sethumadhavan SP, Agarwal R, Anilkumar JM, Pillai AR. Cervical length measurement by transvaginal sonography in predicting preterm labour in low risk women. Int $\mathbf{J}$ Reprod Contracept Obstet Gynecol. 2017;6:5563-7.

25. Reddy SVG, Mudanur SR. Role of cervical length evaluation with transvaginal ultrasound for prediction of preterm delivery in low risk pregnancy. Int J Reprod Contracept Obstet Gynecol. 2018;7:2852-5.

26. Pushparaj S, Nagaraj P. Transvaginal ultrasonographic assessment of cervical length in prediction of preterm labour in high risk asymptomatic women. Int $\mathrm{J}$ Reprod Contracept Obstet Gynecol. 2018;7:4981-6.

27. Lim K, Butt K, Fredericton NB, Crane JM. Ultrasonographic Cervical Length Assessment in Predicting Preterm Birth in Singleton Pregnancies. J Obstet Gynaecol. 2011;33(5):486-99.

Cite this article as: Raval BM, Sisodiya VP, Yadava PA, Mehta ST, Patel SR, Dadhania BH.

Measurement of cervical length using transvaginal sonography for prediction of preterm labour. Int $\mathbf{J}$ Reprod Contracept Obstet Gynecol 2020;9:4471-6. 